points out that none of the sites is ideal by all three criteria, that several are perfectly acceptable and that a different set of criteria might change the order. The report stresses, however, that the acceptable sites are not of equal value.

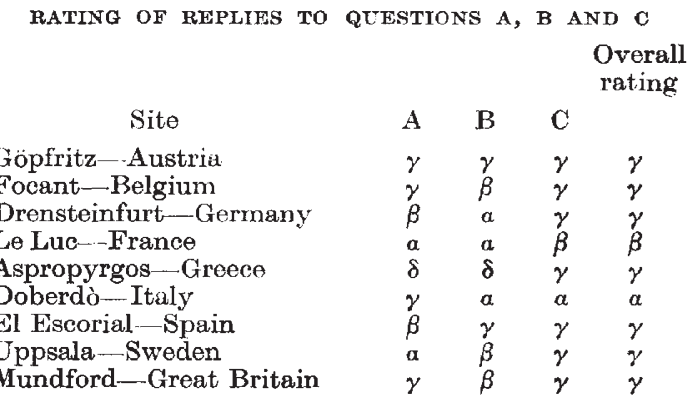

Needless to say, the report has been accompanied by what amount to special pleadings from the delegations of the disappointed countries. The Spanish delegation called for a widening and revision, the Greek delegation contests the view that Aspropyrgos cannot be considered because of the risks of earthquakes, the Austrian delegation disagrees with the geological survey of Göpfritz and the British delegation holds that the cost of construction and operation should be the most important criterion.

\section{Back to Chicago}

THE capability of the National Science Foundation to hold its own in Washington will be further diminished, in October this year, by the departure of Dr John T. Wilson, at present deputy director at the foundation, for the post of vice-president at the University of Chicago. In the past five years, Dr Wilson has become known as a powerful source of new thinking about the policies of the National Science Foundation, and there will now inovitably be speculation that his resignation has been prompted as much by the frustrations of his work in Washington as by the attractions of Chicago.

Since the war, Dr Wilson has alternated between the foundation and Chicago. He was assistant director for biological and medical sciences at the foundation from the mid-fifties until 1961, when he became a professor of psychology at Chicago and special assistant to the president of the university, Dr George Beadle. In his new post as vice-president of the university, he will be responsible for the academic administration. If his experience and temperament are any guide, he will expect to play an important part in the development of a strategy for the development of the university under its new president-designate, Dr Edward Levi.

Dr Wilson's departure from the foundation may well bring into the open some of the continuing doubts about the management of the foundation which are now widely shared among scicntists in the United States. There is much to support the view that the direction of the foundation has been less than adequate since its establishment in 1950. For the first decade or so, under the late Dr Alan T. Waterman, the foundation was perhaps unduly and unwisely preoccupied with the problems of support for fundamental research, and too little concerned with the relations between research and education on one side and government on the other. More recently the foundation's influence seems to have been needlessly muffled. On one view, the continuing ill-health of the present director, Dr L. J. Haworth, is a part of the trouble. Elsewhere it is held that a more thorough recasting of the hierarehy at the foundation may now be necessary.

\section{Postgraduate Biologists}

THE report of the biology sub-committee of the committee of the Royal Society which is surveying postgraduate training in science and technology, the third of six, has just been published. Faced with the problem of surveying the multitude of specialized disciplines which came under the umbrella of biology, the subcommittee, under the chairmanship of Professor J. $\mathbf{L}$. Harley of Sheffield University, decided to collect evidence in four ways. It read the propsectuses and proposals of the universities. It sent a questionnaire to the heads of departments and research stations (167 replied), and some heads of departments were also interviewed. 'The sub-committee sent another questionnaire to people who had gained their $\mathrm{PhD}$ degrees in the past five years from five universities. Finally, the committee obtained descriptions of $\mathrm{PhD}$ programmes in North American universities from senior biologists who also knew the conditions in Britain. Clearly, compared with the physics sub-committee which based its report entirely on the replies of heads of departments to a questionnaire, the biology group has spread its net wide.

What are the conclusions? The report says that "British systems of $\mathrm{PhD}$ training in biology are designed essentially for the candidate who is well prepared by his first degree for research and whose success depends principally on his own initiative and that of his supervisor. The systems are not so appropriate to those candidates who are less well prepared, nor to some students from overseas". 'That sounds like a polite way of saying that there are no organized programmes for training $\mathrm{PhDs}$ but rather an apprenticeship system in which making a shrewd choice of supervisor at the outset is vitally important. This is borne out by the two recurrent themes in the suggestions for improvements sent to the sub-committee. They are, first, to improve the system of supervision and, sccond, to increase the number of lectures and seminars for postgraduates.

Altogether, 90 per cent of the recent $\mathrm{PhDs}$ recognized that some formal instruction is now necessary, but fewer than 10 per cent of the 167 departments in the survey run lecture courses specifically designed for postgraduates. The most favoured proposal, which the sub-committee endorses, is for unexamined lecture courses and surveys spread over the first two years of postgraduate study. And, because the standard of the first degree is usually higher in Britain than in the Unitcd States, such courses need not be on the scale of those in American $\mathrm{PhD}$ programmes. In contrast with the views of recent PhDs, the senior staff of 40 per cent of the departments consulted were against formal instruction. They no doubt fear the extra teaching load and, as the report points out, the chief reason for the present situation is the small size of most departments, the staff of which is fully committed to undergraduate work. This, coupled with the small 
numbers and diverse interests of postgraduates, often makes special postgraduate courses impracticable and uneconomic. The sub-committee is obviously right in saying that eloser interdepartmental collaboration is the answer to these problems.

The sub-committee has also unearthed figures which show the alarming, in fact disgraceful, paucity of seminars and colloquia in biological departments. Only 78 per cent of the departments hold seminars during term--18 per cent weekly, 18 per cent monthly and the rest presumably less often. That 82 per cent of British biological departments only average at best a monthly seminar, and that 22 per cent apparently have no regular seminars at all, speaks for itself. Small wonder that the report urges that such meetings, which are vital for any thriving department, should be more frequent and inter-departmental where possible.

"Good supervision is the keynote of a good $\mathrm{PhD}$ system." It is typical for the postgraduate student to see his supervisor several times a week, if not daily.

The sub-committee considers that "supervision cannot be improved fundamentally by legislation" but nonetheless it says it would be useful to formulate minimum requirements for meetings between students and supervisors. In its subdued way, it also proposes that having committees of three to five supervisors, as is common in the United States, should be considered. This system exposes the postgraduate to a wider range of factual knowledge and, more important, to a wider range of experimental skills and approaches without necessarily excluding the personal responsibility of one supervisor for one particular student. Indeed, where there is a clash of personalities, the committee system would be an enormous improvement. As things are, it is extremely difficult for a student to change his supervisor, no matter how badly they get along with each other.

As to the PhD examination itself, although there is concern, especially among recent $\mathrm{PhDs}$, that the standards of the degree and the methods of examination are too variable, the report makes no recommendation for change. Arguments for and against the supervisor being an examiner, and whether or not all examiners should be external, are equally balanced, and most departments were not in favour of classifying the PhD degree except for possibly giving a mark of distinction to outstanding theses. It seems that 99 per cent of PhDs in biology are completed in three years and only 1 per cent take longer, so the subcommittee, unlike the physics sub-committee, does not recommend provisions for fourth year grants. Again in contrast to the physics sub-committee, the biologists believe that, so long as standards are not diminished, changes in the present three year honours degree are not necessary. The first degree in biology apparently still provides a satisfactory grounding for $\mathrm{PhD}$ training.

\section{Old Age}

RETIRED people now make up more than 12 per cent of the population of Britain. During this century the four-fold increase of people in this age group has far outpaced the increase in lower age groups, although the life expectancy of a 65 year old has only increased by 2 years, while that for a baby has increased by 24 years. More than three-quarters of the 300,000 old people who live alone do not have the help at home which they think they need and many thousands are in need of medical attention. The Office of Health Economics (OHE) has been studying the facts, figures and problems of old age and makes suggestions as to how the lot of old people can be improved, in its latest paper Old Age (OHE, 2s. 6d.).

The main priority, the report suggests, is to improve the quality of old people's lives rather than to prolong them. At present, care of the old costs more than $£ 1,650$ million a year in Britain, $£ 400$ million of this being medical care which takes 30 per cent of the National Health Service budget. Healthier old people will not only mean happier old people, but a lighter burden on the community. If people over 65 become generally healthier, the retiring age could be raised. Two particular lines of approach are discussed in the report-the provision of better welfare services for those who are now old and further attempts to prevent illness that will incapacitate people when they get old. Research is required in both directions. As well as the obvious investigations into disease and the nature of ageing, the sociological effects of old age must be studied in connexion with housing, health and ignorance of how help can be obtained. The OHE recommends that a national council could be set up to co-ordinate the various aspects of research, as a multidisciplinary approach would be most effective.

The OHE, sponsored by the pharmaceutical industry, is an independent organization which undertakes research on various economic and social aspects of medical care. Old Age is its twenty-sixth publication, earlier papers having covered such topics as mental health, polio, drug addiction and medical manpower. The director of OHE, Mr G. Teeling-Smith, suggests that although the study of old age has less glamour than work with children, it can improve the quality of the retirement years that face us all.

\section{Defence Research}

\section{from our Parliamentary Correspondent}

WITH three public sessions gone, and perhaps twice as many in private, the Select Committee on Science and Technology has learned one thing at least: the civil servants responsible for defence research are unanimous in their approval of the way it is done. Mistakes, it seems, are a thing of the past, banished by the adoption of the Gibbs-Zuckerman procedures, as the techniques of assessment are called. This may be true, but the committee would be doing less than its duty if it believed it without independent corroboration. Unfortunately, all those who are familiar with the system have an interest in saying how good it is. What the committee needs is a company disenchanted with the Ministry of Defence. During the most recent session, on March 21, a possible candidate emerged-the hovercraft industry, which seems to have met with little encouragement from the ministry.

On March 21, the committee interviewed five representatives from the ministry. Most of the questions were on organizational minutiae-the operational requirement committee, eight strong, meets weekly, while the weapons development committee, nineteen strong, gets together every fortnight. The witnesses agreed to supply three case studies showing how three projects came to fruition-the CVRT armoured vehicle, the Nimrod aircraft project, and the Type 42 destroyer. 